\title{
RECURSOS DIDÁTICOS NO ENSINO DE HISTÓRIA: NAS ESCOLAS DE CAMPO ALEGRE DE LOURDES -BA
}

\section{ARTIGO ORIGINAL}

BASTOS, Manoel de Jesus ${ }^{1}$

BASTOS, Michelly de Jesus ${ }^{2}$

BASTOS, Manoel de Jesus. BASTOS, Michelly de Jesus. Recursos didáticos no ensino de história: Nas escolas de Campo Alegre de Lourdes -BA. Revista Científica Multidisciplinar Núcleo do Conhecimento. Ano 05, Ed. 06, Vol. 11, pp. 0520. Junho de 2020. ISSN: 2448-0959, Link de acesso: https://www.nucleodoconhecimento.com.br/educacao/didaticos-no-ensino

\section{RESUMO}

O presente trabalho aborda assuntos inerentes aos recursos didáticos para a disciplina de História nas escolas do município de Campo Alegre de Lourdes - BA. No decorrer da pesquisa pôde-se observar as suas imensuráveis importâncias na ministração das aulas bem como as suas carências e o comodismo de busca e aplicabilidade por parte de alguns professores. O mesmo objetiva mencionar a eficácia desses recursos nas aulas de História, ao tempo em que apresenta inquietações a respeito de suas ausências nas escolas do município. A metodologia utilizada apresenta abordagem quantitativa, pois busca a validação das hipóteses; quanto aos objetivos, exploratória, uma vez que procura explicitar o problema com maior precisão; além de embasamento bibliográfico e de algumas entrevistas. É sabido que o uso

1 Mestre em Ciências da Educação, Pós-graduado em Supervisão Escolar pela Faculdade de Teologia Hokemãh - FATEH, Licenciado em Normal Superior pela Universidade Estadual do Piauí - UESPI.

${ }^{2}$ Graduada em História pela Universidade do Estado da Bahia - UNEB através da Universidade Aberta do Brasil - UAB. 
correto de materiais de ensino viabilizará uma aprendizagem mais prazerosa e qualitativa no âmbito escolar, cabendo aos professores, sobretudo de História, saírem de suas zonas de conforto e angariarem essas ferramentas para oferecerem aulas mais atraentes e produtivas aos seus alunos. Aulas expositivas, despidas de quaisquer recursos concretos, poderão gerar o desconforto e a anorexia escolar nos discentes. Para a realização deste trabalho, comungou-se com alguns estudiosos que nortearam e deram suporte teórico.

Palavras-chave: História, materiais didáticos, ensino-aprendizagem.

\section{INTRODUÇÃO}

A História é uma disciplina tão útil quanto as demais que compõem o currículo escolar e contribui, da mesma forma, com a formação da cidadania, prevista na Constituição do Brasil. Faz parte das ciências humanas e analisa a vida do homem com base na linha do tempo. Quando se investiga o passado dos seres humanos, como eram, o que faziam, como se socializavam, etc., está se desenvolvendo um trabalho dentro dessa ciência. Ela é resultado de um passado contemporâneo ou extemporâneo, construído pela humanidade.

Através desta disciplina é possível compreender a origem dos povos, o surgimento de nossa cidade, do nosso estado, de nosso país e de outras gerações e continentes. Com embasamento na História podemos entender a sua influência e contribuição, ao longo dos séculos, para o crescimento sociocultural, científico e tecnológico. Para Aguiar (2012),

A História é feita por homens, mulheres, crianças, ricos e pobres; por governantes e governados, por dominantes e dominados, pela guerra e pela paz, por intelectuais e principalmente pelas pessoas comuns, desde os tempos mais remotos. A História está presente no cotidiano e serve de alerta à condição humana de agente transformador do mundo. (AGUIAR, 2012. Pág. Não encontrada) 
Diante do exposto acima mencionado pelo teórico e por comungar com a sua concepção, surge a inquietação e a sensibilização pela importância dos materiais didáticos no ensino de História, sobretudo nas escolas de Campo Alegre de Lourdes. Considerando o uso desses materiais, uma vez bem utilizados, como suporte de concreticidade, defende-se que os professores de História saiam de suas zonas de conforto e angariem essas ferramentas para oferecerem aulas mais atraentes e produtivas aos seus alunos.

E para nortear este trabalho, resolveu-se questionar: Qual a importância dos recursos didáticos no ensino de História? Quais consequências surgiriam com a ausência desses recursos? O que fazer para conseguir essas ferramentas e adequá-las a sua aplicabilidade?

É sabido que o uso correto de recursos que venham auxiliar às atividades humanas, viabilizará a efetivação da didática, uma vez que didática e teoria são indissociáveis, ou seja, caminham paralelamente. Utilizar recursos numa aula de História, explicitará com muito mais nitidez o assunto em trâmite, além de gerar curiosidade e, consequentemente, motivação por parte do aluno.

O professor que se acomoda com suas aulas simplesmente expositivas, despido de qualquer recurso concreto, poderá gerar o desconforto e a anorexia escolar nos seus alunos. Acredita-se que a ausência de suportes que venham facilitar o relacionamento científico entre professor/aluno, propiciará a quebra de ponte entre ambos, dificultando, sobremaneira, o que se quer ensinar e o que se quer aprender.

A carência de recursos didáticos, sobretudo os tecnológicos, para o ensino de História nas escolas de Campo Alegre de Lourdes é fato, porém o professor precisa deslocarse de sua zona de conforto e desenvolver estratégias para consegui-los. Contudo, apesar das dificuldades existentes, já foi muito mais difícil. Atualmente, o wifi encontrase disponível em, praticamente, todos os extremos do município, o que facilitaria a impregnação de pesquisas inerentes à disciplina. Há um museu intitulado "Museu da Natureza", localizado a pouco mais de 100 quilômetros, no estado do Piauí, 
considerado grande fonte de pesquisa e que poderia ser visitado, pelo menos uma vez/ano, pelos alunos de História, mediante projeto dos historiadores.

Todavia, um planejamento coletivo, em parceria com a Secretaria Municipal de Educação - SME, seria a essência para a superação desses déficits. É claro que à proporção em que se avança na busca de recursos didáticos distintos, surge também a necessidade de recursos financeiros, para a cobertura de despesas, o que é considerado normal.

Adotou-se as seguintes hipóteses, para a realização do presente trabalho: a partir do momento em que o professor de História descobrir a importância do uso de recursos de apoio para ministrar suas aulas, desvendará, ao mesmo tempo, que os seus alunos tem dentro de si, algo, que se despertará com a motivação extrínseca por parte do professor; a utilização de ferramentas didáticas nas aulas de História, uma vez bem trabalhadas, atenuaria consequências graves e obstruidoras do ensinoaprendizagem; o professor não deve, em hipótese alguma, prejudicar os seus alunos pela falta de material didático, cabendo a ele angariar subsídios que possam efetivar as suas aulas e consumar os seus objetivos.

Para Gil (1999), a hipótese é uma resposta ao problema a ser investigado. A origem das hipóteses poderia estar na observação assistemática dos fatos, nos resultados de outras pesquisas, nas teorias existentes ou na simples intuição.

Este trabalho apresenta os seguintes objetivos:

- Geral: Desenvolver metas que viabilizem os recursos necessários para o melhor desempenho docente no ensino-aprendizagem de História.

- Específicos: a) Valorizar os recursos didáticos nas aulas de História, angariando-os de acordo à necessidade; b) Propor planejamento coletivo para a superação dos déficits dos materiais didáticos no ensino de História e c) Refletir sobre a imprescindibilidade dos recursos didáticos nas aulas de História: seus efeitos e resultados. 


\section{A IMPORTÂNCIA DOS RECURSOS DIDÁTICOS NO ENSINO DE HISTÓRIA}

A utilização de recursos didáticos para o ensino-aprendizagem na disciplina de História, no cenário do sistema educacional brasileiro, foi sempre imprescindível para a viabilização de melhor aproveitamento, tanto no trabalho pedagógico como no andragógico. E por assim saber, aumenta cada vez mais a preocupação pela sua ausência ou indisponibilidade nas escolas municipais de Campo Alegre de Lourdes, uma vez que não basta os abstratos conteúdos, livros, giz e lousa.

No entanto, admite-se que há a necessidade de uma reflexão aprofundada sobre a utilidade imensurável da inserção de recursos didáticos e tecnológicos no ensino de História, tendo em vista, que eles poderão proporcionar o apetite, a atenção e o interesse dos educandos para com a aprendizagem. É sabido que quanto mais ferramentas o profissional dispuser para a execução de suas tarefas, maior serão as possibilidades de um resultado qualitativo.

A realização de qualquer atividade requer um planejamento prévio e a utilização de materiais que the dê os subsídios necessários para a sua efetivação. No caso do ensino de História o uso de recursos didáticos poderão facilitar a leitura de mundo dos alunos, ampliando-a além de favorecer a ação de criticidade.

É evidente que não basta o professor lançar mão de qualquer recurso para abrilhantar ou, simplesmente, colorir suas aulas; é necessário que seja feita uma seleção criteriosa do material e que esteja, é claro, de acordo com o que se está objetivando. A sintonização entre esses recursos e o tema a ser trabalhado deve ser levado em consideração.

Por ser a História uma disciplina de conteúdos, muitas vezes, ultrapassados, carece da retomada de novos estudos, auxiliados por pesquisas que, comumente, exige recursos didáticos distintos para a viabilização dos resultados. Considera-se que a ausência de suportes didáticos no ensino de História, inviabilizará o desempenho do 
processo. Por assim ser, é preciso primar por recursos didáticos que venham, de fato, proporcionar a personificação dos almejos, tanto do professor, quanto dos alunos.

A insuficiência de recursos auxiliares nas escolas podem contribuir com a desmotivação intrínseca dos alunos e gerar, como consequências, a evasão e a retidão escolar. Eles possibilitarão a conexão entre os discentes e assunto abordado, facilitando, de certa forma, o interesse e a compreensão.

O município de Campo Alegre de Lourdes, possui mais de 20 (vinte) escolas com funcionamento da segunda etapa do ensino fundamental, além de um colégio estadual que oferece o ensino médio. Em entrevista (apresentada adiante) com alguns professores da rede municipal e estadual, que ministram aulas de História, concluiuse que os materiais de ensino disponíveis à disciplina são, realmente, insuficientes para atender às necessidades do ensino, uma vez que os mesmos são itens favorecedores da motivação e do interesse dos alunos.

Tomando como ferramentas que venham auxiliar no processo de ensino, ou seja, motivar e estimular os alunos, o professor deve adequar os recursos didáticos. Ele precisa saber o que condiciona melhor ao seu público alvo e o que pode propiciar os melhores resultados. Independentemente do método em que ele utiliza, os recursos de ensino farão a diferença na impregnação do assunto abordado. Para o psiquiatra William Glasser (1925-2013),

Não deve ser trabalhada só a memorização, pois o aluno só recorda 10\% do que lê, $20 \%$ do que ouve, $30 \%$ do que vê, $50 \%$ do que vê e ouve em simultâneo, $70 \%$ do que discute com os outros, $80 \%$ do que faz e $95 \%$ do que ensina aos outros. (GLASSER, 1925-2013) 
Figura - 01

\section{Tabela de Glasser}

\section{MANEIRA DE APRENDER}

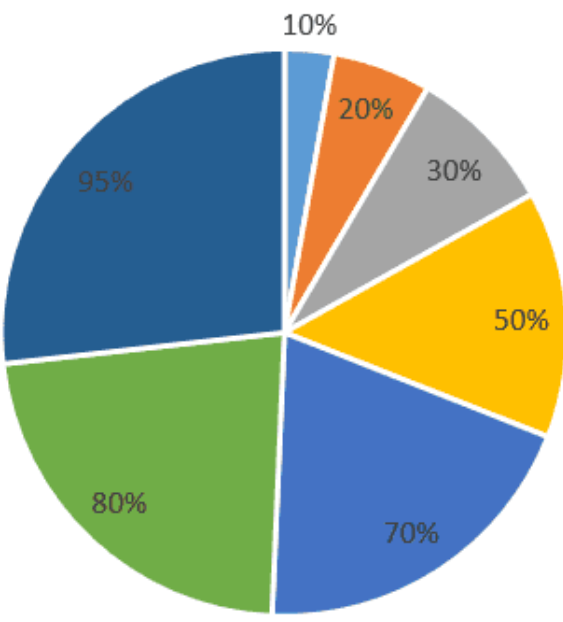

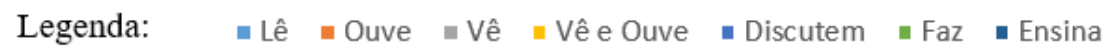

Fonte: Informação elaborada pelo autor

Com base nessa teoria, Glasser criou uma pirâmide para explicitar melhor o grau de aprendizagem dos alunos. 


\section{PIRÂMIDE DE WILLIAM GLASSER}

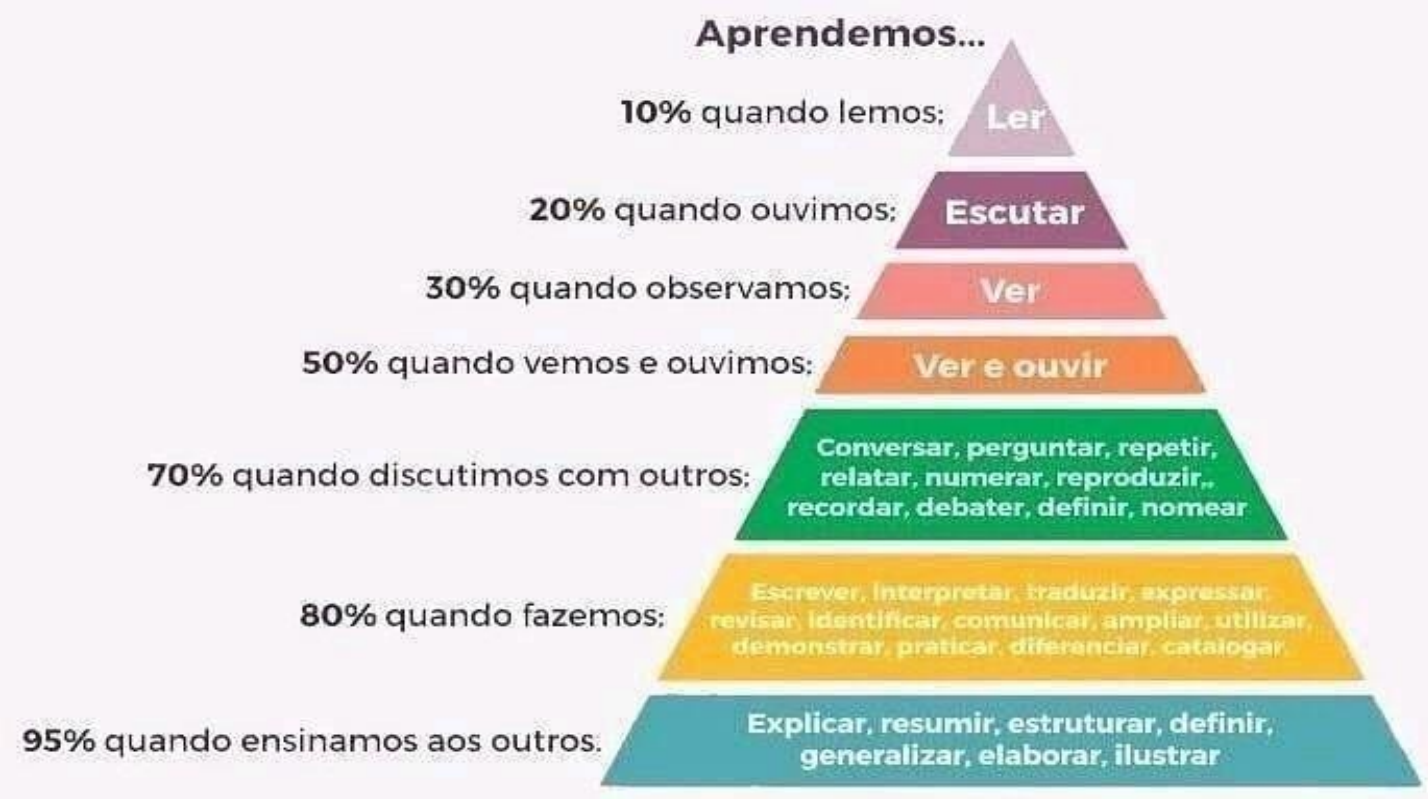

Fonte: CEESD

Há uma gama de recursos didáticos imprescindíveis ao ensino de História e que podem ser classificados como:
$\left[\begin{array}{l}\text { - quadro/fichas } \\ \text { - pincel/desenhos }\end{array}\right.$
a) pedagógicos - mapas/livro
- cartazes/gráficos
- cartas/fotografias
b) tecnológicos - internet - projetor
- multimídia
c) culturais
- biblioteca da escola
- exposições
- museus
- pinturas rupestres
- escultura
- artesanato


Contudo, o uso desses recursos precisa variar, de acordo à necessidade, uma vez que a sua utilização excessiva poderia gerar cansaço psicológico, enfadonhamento e desinteresse na turma. A adequação do seu uso tem uma acentuada significância no ensino de História, pois permitirá o encurtamento das aulas expositivas, consideradas chatas e sem sabor, pelos alunos.

No decorrer deste trabalho resolveu-se questionar 46 (quarenta e seis) alunos dos anos finais do Ensino Fundamental ( $6^{\circ}$ ao $9^{\circ}$ ano) de uma escola pública municipal com a seguinte indagação: Qual dos recursos didáticos abaixo utilizados tem facilitado a tua aprendizagem? a( )mapas b( )retroprojetor c( )globo d( )lousa e( )livros $f($ )gravuras

O resultado apontou melhor aproveitamento com o recurso retroprojetor, conforme indicação no gráfico abaixo.

Figura - 02

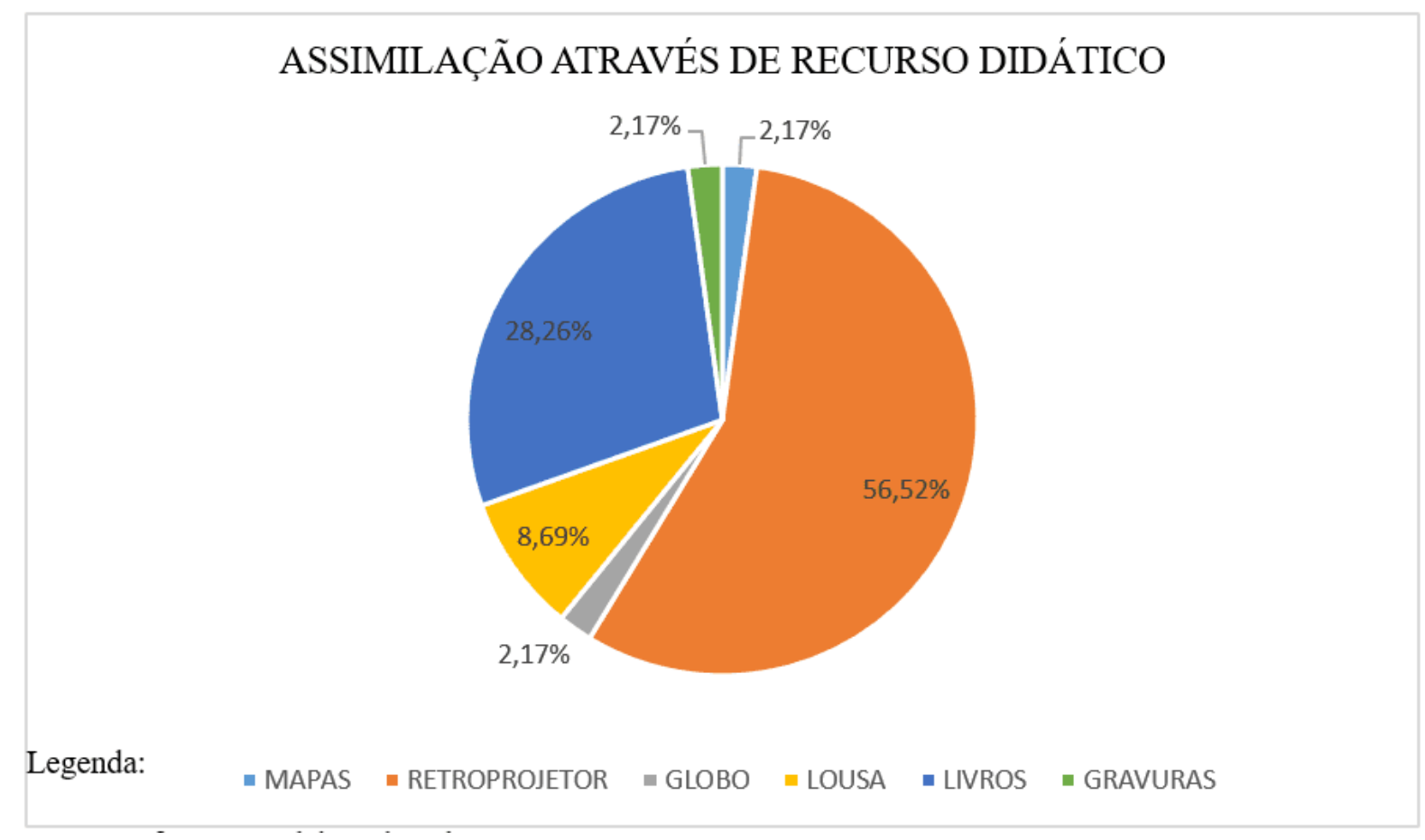

Fonte: Informação elaborada pelo autor 
Daí a importância da utilização de recursos didáticos em trabalhos pedagógicos para melhor assimilação e, consequentemente, melhor desempenho dos discentes. A sua carência, em especial na zona rural, vem empecilhando o desenvolvimento do ensinoaprendizagem, uma vez que não suprem às necessidades dos professores na ministração de suas aulas de História. Com base nisto, questionou-se alguns professores da disciplina sobre a importância desses recursos no ensino de História:

É importante, para que possamos desenvolver um trabalho com grande autonomia dentro do conteúdo estudado, estimulando o aluno a desenvolver o seu conhecimento prévio, levando em conta, que cada material didático proporcione novidades dentro do contexto estudado. Proporciona um desenvolvimento mais amplo dentro do conteúdo, possibilitando melhor criatividade contextual e uma melhor estratégia de ensino na área estudada (PROFESSOR 01)

É de grande importância, pois facilitam a troca de conhecimentos, tornando as aulas mais interessantes, além de melhorar a compreensão dos conteúdos e à interação entre professores e alunos. (PROFESSOR 02)

Outros depoimentos deixam claro que o uso adequado dos recursos de ensino abrirão janelas para a melhoria do desempenho discente, como pontuou a seguinte entrevistada:

Os recursos didáticos, tornam as aulas mais prazerosas e mais significativas, atuando também como facilitadoras do ensino. Permitem que os alunos tenham contato com diferentes formas de aprendizagens, motivando e viabilizando uma aprendizagem significante. (PROFESSOR 03)

Contribuem para facilitar o ensino-aprendizagem. O livro didático é um dos mais simples recurso e faz uma falta enorme se os alunos não o disporem. As tecnologias também nos permitem aproximar os conteúdos 
à realidade, mantendo contato em tempo real e diminuindo à distância entre os discentes. Proporcionam o desenvolvimento da competência leitora e escritora para que entendam que a disciplina não tem o objetivo só de ilustrar ou exemplificar um determinado tema e sim de materiais que devem ser confrontados, comprados e contextualizados. (PROFESSOR 04)

É evidente que não bastam esses recursos didáticos para a efetivação de uma boa aprendizagem na disciplina de História; é necessário que se articule outras atividades como rodas de debates, dramatizações, produções e apresentações de trabalhos, realizações de pesquisas, etc. Esses recursos possibilitarão a expansão da capacidade do senso crítico, argumentação e defesa dos estudantes.

Todavia, uma aula enriquecida com recursos didáticos é como uma refeição bem temperada e que proporciona o apetite, como ressalta o psiquiatra TIBA (2006),

O professor, qual um bom cozinheiro, poderia preparar a aula com preparativos e entradas, antes de servir o prato quente, e culminar com a sobremesa. Mesmo sem entradas nem aperitivos, se a aula for bastante prazerosa, todos sentirão vontade de absorvê-la. Portanto, a palatabilidade é muito importante. (TIBA, 2006, p. 41)

Dentre os recursos didáticos úteis às aulas de História, acredita-se que a internet é a que aparece como essência, pois não basta a pesquisa em fontes escritas e talvez ultrapassadas, uma vez que novos estudos e/ou novas pesquisas tendem a divulgar resultados com supostas mudanças relacionadas ao que se sabia. Por ser a História uma disciplina com suposta mutacionalidade, carece de estudos inovadores.

A exemplo dos costumes do índio que, certamente, já não é mais aquele primitivo, da toca, do comer carne crua, de sobreviver simplesmente da caça etc. É sabido que esses povos mudaram algumas atitudes, alguns costumes e hábitos; assim como a população de determinado território, divulgada pelo censo, há alguns anos, já não é mais a mesma. 
O artigo 26-A da LDBEN prevê:

Nos estabelecimentos de ensino fundamental e médio, públicos e privados, torna-se obrigatório o estudo da história e cultura afro-brasileira e indígena.

$\S 1^{\circ}$ O conteúdo programático a que se refere este artigo incluirá diversos aspectos da história e da cultura que caracterizam a formação da população brasileira, a partir desses dois grupos éticos, tais como o estudo da História da África e dos africanos, a luta dos negros e dos povos indígenas no Brasil, a cultura negra e indígena brasileira e o negro e o índio na formação da sociedade nacional, resgatando as suas contribuições nas áreas social, econômica e política, pertinentes à História do Brasil. (LDBEN, art. 26-A)

Nessas circunstâncias, concretiza-se a importância e a necessidade da internet, como recurso didático, para pesquisas de conteúdos referentes à disciplina para posteriores resultados atualizados e eficientes. Ignorar esse aplicativo, contemporâneo, é estar mascarando a si mesmo e a sociedade.

Apesar da sua imprescindibilidade, a internet ainda parece ser o bicho-papão para muitos professores que a ignoram ou simplesmente acomodam-se deixando de buscar o novo, mas preferindo o velho. São esses descuidos ou comodismos que fazem com que o ensino de História patine numa bitolação, ano após ano, gerando, como consequência, uma indigestão escolarizativa.

\subsection{A INSUFICIÊNCIA DOS RECURSOS DIDÁTICOS NO ENSINO DE HISTÓRIA NAS ESCOLAS MUNICIPAIS DE CAMPO ALEGRE DE LOURDES -BA}

Atualmente vivencia-se o século tecnológico do celular, do whatsApp, do tablete, do wifi, etc., onde fica inviável trabalhar apenas com o livro, o quadro e o giz. O professor está incumbido a planejar aulas inovadoras que possam despertar interesse e atração 
nos seus educandos. A hodiernidade exige que se utilize materiais de caráter instrumental, sejam objetos físicos ou abstratos. De acordo com Piletti (2005),

Quando usamos de maneira adequada, os recursos de ensino colaboram para:

a) Motivar e despertar o interesse dos alunos;

b) Favorecer o desenvolvimento da capacidade de observação;

c) Aproximar o aluno da realidade;

d) Visualizar ou concretizar os conteúdos da aprendizagem;

e) Oferecer informações e dados;

f) Permitir a fixação da aprendizagem;

g) Ilustrar noções mais abstratas;

h) Desenvolver a experimentação concreta.

(PILETTI, 2006, p. 154)

Todavia, surge a inquietação a respeito da insuficiência de materiais educativos, no ensino de História, nas escolas de Campo Alegre de Lourdes, justamente por saber da sua imprescindibilidade na integração entre professor/aluno/conteúdo. Entende-se que quanto mais diversificado for uso de materiais didáticos em uma aula, maior será a integração dos alunos com o assunto exposto e com a produção de conhecimentos.

Diante dessas inquietações, comunga-se com a concepção de Barreto (2005), quando pontua: "Quando há interação com a tecnologia, ou com o suporte da informação, as pessoas realizam reflexões e passam a buscar conceitos intimamente ligados à informação que receberam até então." A carência de material didático pedagógico/andragógico nas aulas de História, podem empecilhar o desenvolvimento 
do ensino-aprendizagem, cabendo ao professor angariar meios para fazer com que suas aulas se tornem mais prazerosas e produtivas.

Nessas circunstâncias, o professor de História deve lançar mão do que estiver ao seu alcance e produzir os recursos didáticos prioritários que possam influenciar a integração entre professor/aluno/conteúdo e gere, consequentemente, um aprendizado qualitativo. Defende-se que em pleno século tecnológico e de conhecimento globalizado, extrapole-se o limite de exposição oral, nas aulas rotineiras e, muitas vezes, consideradas chatas e desprovidas de qualquer motivação, e partase para um trabalho mais dinâmico e mais concreto.

É sabido que a didática consiste nos métodos utilizados pelo professor, com base em teorias que possam, evidentemente, facilitar a aprendizagem dos seus alunos. Teoria e prática são caminhos indissociáveis, ou seja, um depende do outro para a efetivação de um planejamento.

A aplicabilidade da didática, ora fundamentada na teoria, realizará o papel íntegro do professor no âmbito educacional, com direcionamento ao seu público alvo, visando estimular a fomentação do aprender. É um projeto saindo do papel rumo a sua efetivação. (Grifo nosso)

No entanto, o uso adequado desses materiais (recursos didáticos) em uma aula de História, retribuiria num resultado mais aproximado daquele que se almeja. Essa prática propiciaria em um elo recíproco entre o professor, a disciplina e o aluno, consolidando, assim, no verdadeiro ensino-aprendizagem.

Os recursos didáticos é uma amostragem do que se pretende ensinar, tornando as atividades muita mais divertidas e mais prazerosas além de motivar os alunos ao interrelacionamento. De modo que quanto mais houver diversificação desses recursos, maior será a geração de curiosidades dos alunos. Curiosidade gera interesse e interesse gera aprendizagem. 


\section{OS RECURSOS DIDÁTICOS NO ENSINO DE HISTÓRIA NA CONTEMPORANEIDADE}

No presente século, há uma necessidade muito grande de se repensar o papel do ensino-aprendizagem em todas as áreas curriculares, sobretudo a de História, uma vez que os métodos tradicionais se encontram, meramente, ultrapassados. Além do crescimento da demanda houve, também, a expansão de expectativas pela busca de resultados eficientes e rápidos. Nesse cenário, o professor necessita incorporar esses recursos em suas aulas, assim, como o cozinheiro incorpora os temperos na comida, com a intenção de fomentar e gerar o apetite dos seus clientes.

Comungando com o teórico TIBA, disponibilizar de recursos de ensino adequadamente, considerando a imprescindibilidade de sua diversificação é, analogicamente falando, os temperos que, de certa forma, provocarão o apetite necessário ao processo de ensino-aprendizagem. As chances de assimilação do que se vê, se manipula, se discute e se realiza, com a orientação de um profissional, é muito mais ampla, além de proporcionar qualidade.

Os recursos didáticos são ferramentas que consolidam a teoria à prática e com maior probabilidade de eficiência, desde que não se limite aos mesmos. A sua incorporação no âmbito do ensino de História, deve ser considerada como mera estratégia da política pedagógica/andragógica e dispositivo das inovações propiciadoras do desenvolvimento educacional.

É inadmissível trabalhar História, na contemporaneidade, tendo como embasamento fontes ultrapassadas, uma vez que o novo brota sem parar. Morin (2011), usou a frase de Eurípedes: "Os deuses criam-nos muitas surpresas: o esperado não se cumpre, e ao inesperado um deus abre o caminho." Atualmente, há uma gama de recursos didáticos, inclusive tecnológicos, que favorecem resultados atualizados e precisos, se, no entanto, forem utilizados de forma adequada. Ademais, a utilização de recursos ultrapassados, no ensino de história como, por exemplo, livros editados a dezenas de anos, mapas com legendas antigas ou a história de algo que já sofreu algumas alterações, mediante a outras teorias, proporcionaria uma aprendizagem deficitária. 
Todavia, a História encontra-se narrada em uma diversidade de fontes: relatos, músicas, culturas, livros, biografias etc., mas é preciso que o professor procure as melhores estratégias para facilitar o ensino-aprendizagem da disciplina, escolhendo ou pesquisando recursos didáticos que sirvam como ferramentas que proporcionem um trabalho proveitoso e qualitativo. Recursos didáticos novos despertarão curiosidade nos alunos e é essa curiosidade que proporcionará a aprendizagem, pois a inovação gera, a motivação.

É sabido que os resultados daquilo que se realiza com prazer são bem melhores e apresentam uma qualidade imensurável. O comodismo e/ou a falta de criatividade do professor gera desconforto e desinteresse nos alunos. É como comer sempre a mesma coisa, o que geraria certo enjoo, falta de apetite ou coisa semelhante. Adicionar algo diferente não deixa de ser um chamativo, um experimento do novo e com condições de proporcionar surpresas agradáveis.

Com os avanços tecnológicos vivenciados hodiernamente, é imprescindível que se utilize materiais didáticos que possam favorecer subsídios à viabilização do ensinoaprendizagem em todas as disciplinas, sobretudo a de História, por considerá-la a "ciência do homem no tempo." São esses materiais que garantirão com muito mais segurança e com a probabilidade de menos equívocos, a história do futuro.

É preciso reconhecer que em relação à linha do tempo, perdeu-se registros de muitos acontecimentos importantes, ao longo dos séculos, pela escassez ou ausência de repositórios que garantissem, com segurança, a sua preservação. A exemplo disso, os homens pré-históricos, das cavernas, que se expressavam de maneira, meramente, primitiva e/ou das pinturas rupestres em pedras arenosas, que se desmoronaram com o efeito erosão.

A credita-se que a contemporaneidade vem oferecendo recursos com a probabilidade de se escrever uma história mais coerente para as gerações futuras, tendo em vista, a diversidade de fontes, inclusive, eletrônicas, para seus respectivos registros. Se antes dispunham-se apenas de papel (papiro na Grécia), atualmente há uma mega 
oferta de fontes mais seguras como os e-mails, pendrives, CDs-ROMs, cartões memórias, fotos e filmes em HD (alta definição), etc.

A presença do professor foi sempre interessante em sala de aula, com exceção em outros tipos de educação como a informal ou a não formal (APETs), além dos cursos EAD, onde a sua presença tornou-se virtual. O que precisa mudar é a forma de ministrar aulas, com a inovação de recursos didáticos, tanto concretos quanto digitais. Ressalta-se aqui, que essa necessidade se dá por saber que o papel do aluno também se modificou mediante as tecnologias que não cessam de aparecer.

\subsection{VALORIZAR OS RECURSOS DIDÁTICOS TECNOLÓGICOS PARA MELHORAR A APRENDIZAGEM}

Atualmente, vive-se o século da modernidade, da globalização e da tecnologia de ponta onde as partes do planeta interligam-se com apenas um clique. É comum observar crianças e jovens manipulando celulares, tabletes, TVs SMART, além de outros dispositivos, em busca de novidades que satisfaçam as suas curiosidades. E nesse contexto, cabe aos professores, responsabilizarem-se pela busca de aperfeiçoamentos que Ihes ofereçam possibilidades de lidar com tecnologias emancipadoras do ensino-aprendizagem.

Como diz o grande teórico Morin (2011): "A incapacidade de organizar o saber disperso e compartimentado conduz à atrofia da disposição mental natural de contextualizar e de globalizar." Contudo, os recursos de ensino podem até estarem próximos do professor, o professor é que, muitas vezes, está distante deles. Talvez por comodismo ou por achar que dá trabalho organizá-los para a apresentação de uma aula inédita, termina mergulhando na monotonia, com aulas enfadonhas e mal degustadas pelos alunos.

Fazer menção aos recursos de ensino, lançando mão do que estiver ao seu alcance, (e olhe que a tecnologia globalizou) criando, confeccionando, buscando, pesquisando, solicitando... não passa do dever de um profissional que se preocupa com a 
aprendizagem que o aluno precisa, ao tempo em que estaria cumprindo com o que prevê o art. 205 da Constituição Brasileira:

A educação, direito de todos e dever do Estado e da família, será promovida e incentivada com a colaboração da sociedade, visando ao pleno desenvolvimento da pessoa, seu preparo para o exercício da cidadania e sua qualificação para o trabalho. (C. F. 1988, art. 205)

Nessas circunstâncias, torna-se, obviamente, necessário uma luta coletiva, com a criação de metas que norteiem os rumos da educação prevista na Constituição. Sendo o professor o principal responsável pelo direcionamento científico, cabe a ele, lançar mão de todas as ferramentas necessárias que possam, de fato, auxiliá-lo em suas atividades, melhorando-as.

\section{CONSIDERAÇÕES FINAIS}

Por considerar a imensurável importância dos recursos didáticos nas aulas de História, torna-se quase que inviável a realização de um trabalho com a isenção dos mesmos. O angariamento por essas ferramentas facilitadoras do ensinoaprendizagem faz-se necessário, desde a solicitação na Secretaria Municipal de Educação - SME, à criatividade de cada professor.

Comungando com a teoria de GLASSER, anteriormente mencionada, as aulas expositivas não seriam suficientes, uma vez que os alunos só assimilam $20 \%$ do que ouvem, mas $50 \%$ do que veem ouvem. Daí a imprescindibilidade da impregnação dos recursos de ensino para uma aula prazerosa, motivadora e explícita, ou seja, uma aula temperada com todos os ingredientes geradores de fomentação e capaz de atender às necessidades dos alunos.

Diante das dificuldades existentes, da escassez desses materiais e, muitas vezes, da acomodação de muitos profissionais que terminam desconsiderando as suas importâncias nas aulas de História, é preciso que se busque alternativas que venham atenuar essas dificuldades; que se crie estratégias voltadas à melhoria do ensino de 
História nas escolas de Campo Alegre de Lourdes. Ademais, a solicitação de cursos de aperfeiçoamento, de materiais didáticos, de wi-fi nas escolas rurais e de outros insumos que viabilizem o norteamento do ensino de História, junto a SME, seria uma possibilidade.

Todavia, não se pode, em hipótese alguma, adentrar em uma atividade despido de ferramentas auxiliadoras do trabalho a que se pretende realizar. Isento delas essa atividade poderia até ser realizada, porém com certa ineficiência e com resultados que não atendem os requisitos almejados.

No entanto, as aulas ministradas pelos professores, sobretudo na disciplina de História, ganharão sabor a partir do momento em que passarem a serem recheadas de materiais que propiciem, de certa forma, a integração dos alunos no assunto, que ofereçam exatamente o que eles precisam para uma compreensão sólida e científica. O professor que se preocupa com a inovação de suas aulas, que procura diversificar os seus materiais didáticos, certamente obterá melhores resultados.

\section{REFERÊNCIAS}

AGUIAR, Lilian. http:www.escolakids.com/a-importância-de-se-estudar-a-história.

BARRETO, A. A. A estrutura do texto e a transferência da informação. Datagramazero, Rio de Janeiro, v. 6, n. 3, p. 1-14, 2005.

BRASIL, Constituição Federal 1988. Constituição da República Federativa do Brasil. Brasília: Senado, 1988.

BRASIL, LDBEN: Lei de Diretrizes e Bases da Educação Nacional. Lei oํ 9.394/96 de dezembro de 1996.

GIL, Antônio Carlos. Métodos e técnicas de pesquisa social. São PAULO: Atlas, 1999. 
GLASSER, William. A pirâmide de aprendizagem. William Glasser. Psiquiatra / www.ceesd.org.br

MORIN, Edgar. Os sete saberes necessários à educação do futuro. São Paulo: Cortez, 2011.

PILETTI, Nelson, 1945 - História à vida integrada. Nelson Piletti, Claudino Piletti. São Paulo: Ática, 2003.

TIBA, Içami. Ensinar Aprendendo: novos paradigmas na educação / Içami Tiba. - 18 ed. rev. e atual. São Paulo: Integrare Editora , 2006.

Enviado: Outubro, 2019.

Aprovado: Junho, 2020. 